\title{
Making Sense of Gender in Shifting Institutional Contexts: Some Reflections on Gender Mainstreaming
}

\author{
Ramya Subrahmanian
}

For many speakers at the "Gender Myths and Feminist Fables' conference, on which this IDS Bulletin is based, gender mainstreaming has become a hollow discourse, a generator of myths that simplifies the complexity of gender in ways that are counterproductive, and in many ways a constraint on political action by feminists. These criticisms are not entirely new. As long as gender mainstreaming has been an aspect of the feminist engagement with development, there have been those who have warned of the dangers of political dilution, those that have opposed the takeover of feminist agendas by the state, and the dangers of co-optation. Yet, engagement with the state has been critical for furthering inclusive citizenship and commitments to gender equality and women's empowerment are ubiquitous and often genuine. How do we make sense of these diverse trends? This article offers some reflections on gender mainstreaming, arguing for reviewing its achievements both in the wider context of transformative possibilities, and also in a more modest perspective, scaling down expectations of what it can achieve.

As feminists have sought to alter the terrain of mainstream development, and as this effort has been increasingly internationalised, gender mainstreaming has been the fundamental Gender and Development (GAD) buzzword. The Fourth World Conference on Women held in Beijing in 1995 and the enormous agenda of transformation and change that was identified gave an impetus to a process that had started with the earlier conference in Nairobi. As Staudt (1997: 3) notes, the 'explosion of women's organizational activity and political agenda' unleashed by the UN Decade coincided with developments over time that resulted in states seeking to 'legitimize themselves through public policy and participation-based accountability'. Feminists have, therefore, sought out the state as a key partner for change, and gender mainstreaming has been the label associated with strategies adopted by feminists to make the state an agent of transformative change for women.

Partnership with the state has brought with it clear agendas for feminist action in development, based on reversing the "lens" through which development is analysed, and making explicit the underlying rules of social relationships that have legitimised inequality in resource allocation and redistribution. The agenda for influencing the mainstream includes altering public policies, improving implementation and delivery of policies through clear programmes for change in administrative systems, and directly benefiting women through targeted actions and programmes. This is an ambitious agenda, at the core of which is the effort to advocate for change, through training, institutional mechanisms for making gender a more explicit criterion for development programming and effectiveness, and developing "tools" that can help organisations think more deeply about gender relations, away from the earlier "add women and stir approach". During this time, feminist analysis has also been enriched, partly as a result of greater feminist engagement with mainstream academic institutions and spaces, and has become increasingly more sophisticated, and more politically acute. This has had the effect both of creating greater expectations of state institutions and the gender feminists who occupy advocacy and implementation positions within them, as well as widening the analytical gap between differently located feminist 
advocates. Standing (this IDS Bulletin) links the ever-widening gulf to the supplementary effect that gender feminism has had - the development of intermediaries in this process, such as consultants, and people skilled through higher education and training programmes on gender and development. Gender mainstreaming, as a subset of the development institutional landscape, has itself begun to have implications for both feminist movements as well as development spaces.

The decade of mainstreaming experience has surfaced many lessons. Many of these are about the nature of the state and its institutions, and the kinds of spaces that are available for promoting transformative change. A key criticism about gender mainstreaming has been the "narrowness" of the strategy despite the complexity of gender relations and the contextual variations in the processes and outcomes related to gender inequalities. Most mainstreaming "machinery" looks the same irrespective of the country; most are located at the national level, rarely reaching sub-state levels where development change may be more manageable, and may more closely reflect the needs and priorities of particular sub-groups. The institutional coverage of mainstreaming actors and efforts has been narrowly within the development "industry" - largely within agencies of development cooperation and national governments, thus narrowing the field of engagement often to donor-initiated debates and programmatic interventions. Gender mainstreaming has thus imposed narrowness on what are actually very diverse processes, conflating policy reform with changes in bureaucratic practice, and confining the analytical gaze to the advancement of women's "cause" within institutions with often little mandate and power to effect real change.

A second key criticism has been that gender mainstreaming efforts have necessitated simplifying concepts relating to gender inequality and gender relations, which have in turn fuelled unreal expectations of the ways in which social change takes place. The "implicit" models of social change that continue to hold sway, extend older, and somewhat discredited approaches, which viewed investment of resources in women as the key to their "liberation" from relations of subordination. Messages that gender inequality can be managed through adjustments in bureaucratic practice and policy have necessarily relied on discursive strategies that are "instrumental" - i.e. that suggest that investment in women has high pay-offs. By providing a few "jobs for the girls" in this enterprise, the project of emancipating women was seen to have been set in motion. Quite how this emancipatory project was expected to roll out is not clear. Yet, gender mainstreaming has legitimised this approach in its zeal to portray the achievement of gender equality as a matter of getting development cooperation, development policies and development institutions "right" for women. Mostly, this has resulted in the "conflation of a particular institutional strategy with processes of social change' (WoodfordBerger, this IDS Bulletin).

A third criticism has been about the way in which this implicit model of social change put forward has taken the steam out of the inherently political nature of feminist transformative visions, and has thus meant that "gender" is not seen as explicitly political (unlike, say, race or class), but more as a need to give visibility to women and their capacities and needs. Complaints about policy evaporation - the process through which gender fades out of the explicit commitments and actions that follow rhetorical claims of the importance of gender and development - and the lack of analytical clarity about what "gender" means continue to dominate assessments of gender mainstreaming. Recent literature on international instruments of policy and resource coordination emphasises both analytical weakness and policy evaporation (Whitehead 2003; see Subrahmanian 2004a for a review). The lack of attention to organisational structures is also noted to act as a constraint on following through more impressive policy statements (Kanji and Salway 2000). When the conceptual clarity within organisations attempting to mainstream gender is itself poor, the lack of translation into policy and practice is unsurprising. Gender mainstreaming itself is a hollow term, as its usage commits the user to neither a clear agenda on gender transformative action, nor a clear institutional transformative agenda. This gives rise to highly varied approaches to mainstreaming, and underdeveloped definitions and understandings of what it is that these processes and strategies are meant to achieve.

\section{Placing gender mainstreaming in context}

This discursive "hollowness" may be what makes gender mainstreaming attractive to development agencies (or actors within them), who may prefer 
not to commit to such a demanding transformative agenda, that appears to, regardless of how sophisticated the advocacy discourse that accompanies it, ${ }^{1}$ require some form of disempowerment for men in practice. The notion of the "complementarity" of the sexes in terms of their roles and inclinations is influential, and hard to disembed. Talk of women's empowerment, while attractive because of its progressive ring, also suggests disturbing a particular equilibrium that is often viewed as part of some natural or created social order.

However, the hollowness may also reflect wider economic and political processes, which constrain spaces for transformation, particularly within development institutions. Fine (2003) argues that although the neo-liberal framework has "softened" somewhat based on the criticisms that faced the main Bretton Woods institutions following the perceived failure of their policies to address poverty through structural adjustment policies, not much has changed substantively. Although the postWashington consensus acknowledges the importance of history, institutions, processes and social dynamics as relevant to the understanding of development and change, he argues that the frameworks and intellectual tools still accord primacy to neo-classical economics and the dominance of the market. In analytical terms, economic analysis is now applied to social dimensions of life, resulting in reductionist analysis, i.e. where economic and social relations are interpreted 'through the narrowest of explanatory prisms' (Fine 2003: 7). Within such a hegemonic approach, the objective of complexifying institutional understandings of the ways in which gender impacts on development is doomed not to succeed.

Education provides an illustrative case for examining some of these issues, as it appears at distant glance to represent a success of gender mainstreaming. In education there has been tremendous progress associated with increasing the visibility of gender goals within broader policy efforts. Gender parity, for example, is now widely accepted as a central goal to which governments aspire. International agencies have backed concerted campaigns to promote girls' education. The close proximity of the year 2005, and the target of eliminating gender disparity in primary and secondary education in both the Millennium Development Goals (MDG: Goal 3, target 4) and the Education for All (EFA) goals, has unleashed numerous international reports and conferences. While gender equality in education, a goal for 2015 in the EFA process, is not defined clearly, the impact of gender advocacy on the normative acceptance of gender equality as important to development has been significant. On the redistributive side, too, there have been many gains in terms of efforts to improve female access to education.

However, it is hard to identify the extent to which this change is the result of gender mainstreaming in its narrow sense of coordination mechanisms within bureaucracies. Instrumentalist arguments for girls' education have indeed paid off (the mantra of improved productivity, declining fertility, better child health, better mothering). However, these arguments have arguably thrived because they have conformed to the wider and hegemonic economic discourse within which policy advocacy is played out. Neo-liberal economic discourse is increasingly shaping the way in which policy approaches in other spheres - social policy, governance systems - are evolving. Education has always been particularly prone to this form of ideological capture, given the private nature of the returns arising from investing in it (Subrahmanian 2004b). Several tensions arise. While the case for public investment in education has been fought for and made central to education policy, particularly in the face of human resource crises in many countries, these developments have taken place in contradictory political and institutional environments. The case for universal education (and the attendant realisation that the state is a key agency for this), for example, has been made simultaneous to an assault on the state and its capacities, particularly in the era of structural adjustment. For many, promoting the visibility of women in ways that strengthen policies that continually undermine the conditions under which women are gaining rights is a pyrrhic victory.

This raises the fundamental question of how we should evaluate or assess gender mainstreaming. I suggest that the approach taken should be both broader and more specific. Locating gender mainstreaming (in its composite sense as a set of strategies) within the broader context of development discourses, ideologies and trajectories is important. Equally, insisting on more specific and precise definitions of what these strategies are can only help to clarify the nature of transformation and change that is being pursued. We need to 
simultaneously analyse it from an overarching perspective of the diversity of development processes and actions focused on transformation, and also from within the subset of development it represents, that is efforts to influence aspects of state (and development institution) practice.

Criticisms of gender mainstreaming tend to be focused somewhere in between these two levels of analysis, resulting in an overburdening of expectations on institutions that are inadequate to the task. Not only then does this result in conflating particular institutional strategies with a much larger process of social change, as argued earlier, but it also results in conflating what is in effect a fairly specific set of institutional strategies, practices and processes, with a variety of feminist actions and debates, both within and outside of the state, to influence social change. By characterising gender mainstreaming as a "monolith", and without disaggregating what it entails, who is involved, and what processes and strategies it comprises, in clearly situated contexts, evaluations of "its" effects or impacts become impossible. This "mythical beast" is then invested with the powers to effect social change, and the underlying and implicit assumptions (and models) of institutional and social change associated with it remain uninterrogated. If expectations are scaled down, then the achievements of gender mainstreaming may be more realistically assessed, and may actually be positive in some cases. At the least we may develop a better "handle" on understanding the processes of change that explain certain outcomes, as well as focusing sharper attention on the politics surrounding these processes of change.

Blackmore's (2004) account of educational change in Australia provides an important historical perspective of the phases through which the push for gender equity reform in education has undergone. Her analysis locates specific institutional mechanisms within the context of wider political shifts and policy agendas. She notes that several variables determine the extent to which gender equity reform can succeed - the kind of state, the kind of feminism within which "gender equity" is being advocated, the overarching political ideology of the state, the position adopted about gender inequality, the level of state feminism, the kind of institutional design that is put in place to support reform, amongst others. Her careful periodisation of change in educational policy in Australia shows the fundamental importance of political ideology (a Labour government) and bipartisan feminist advocacy, in creating the fertile ground for state feminism. A key to the promotion of state feminism was the appointment of feminists as bureaucrats. These "femocrats" "were expected to be advocates and their divided loyalty to feminism and the bureaucracy was seen to be good for the state' (Blackmore 2004: 4). Femocrats were key brokers of multi-sited and potentially oppositional strategies. "Top-down/bottom-up" parallel processes helped to create pressure from below as well as initiative from the top. For instance, grassroots activism of feminist teachers and parents' bodies both complemented and challenged the work of femocrats, provoking greater creativity in the development of strategies and initiatives.

Other institutional mechanisms that supported these parallel movements were the integration of the women's unit into government, rather than its isolation as a separate unit, which allowed femocrats to develop 'cross-portfolio initiatives' (Blackmore 2004: 5). Further, the Women's Budget Program made explicit the kind of discrimination experienced by women and redistributive programs by uncovering the low financial allocations. This gave femocrats concrete evidence around which to base claims and advocacy. Further, in line with other developments, the gender equity focus in schools also meshed and refined itself through encounters with other social justice advocacies, including indigenous groups and non-English-speaking groups. As Blackmore notes, this meant that the particular discourses of advocacy and equity reform were themselves transformed: ' $\ldots$.. gender equity reform for girls benefited many students perceived to be "at risk" and indeed came down to being "good pedagogy" for all students by addressing their specific needs' (Blackmore 2004: 7).

However, these changes were not alltransforming. With the underlying discourse being assimilationist (i.e. bringing women into leadership positions), and proceduralist (removing obstacles to girls' advancement) and oriented towards recognition of girls, harder issues such as structural and institutional barriers, though recognised, remained off the agenda. Thus while the infrastructure of change existed at all levels, these were built on the liberal feminist premise which had: 'a focus on improving aspirations, self confidence, skills, and the competence of individual 
women and girls rather than to challenge cultures of masculinity or change schools. The policy problem with regard to gender equity was defined as the problem lying with women and girls ie [sic] a deficit model' (Blackmore 2004: 8).

Blackmore's account offers rich and multi-layered insights, of which the above are only a few. Her subsequent analysis of the discursive and ideological shifts that led to the introduction of neo-liberal and socially conservative policies demonstrates how quickly progressive infrastructure can be made to give way to new pressures. In particular, the impact on the state bureaucracy of performance and outcome-based resourcing policies, and its accompanying discourses of effectiveness and efficiency, have reshaped the concept of "equity". In Australia, the call for gender mainstreaming in this context seems to have set off alarm bells: ' ... the discourse was about mainstreaming of equity that many femocrats opposed as being premature as most managers neither accepted the notion and did not see the lack of women as a problem' (Blackmore 2004: 9). With the return of neoconservative governments both at federal level and in a few states in 1996, equity policies were relegated further to the background, a result of the combination of 'social conservatism (self help, women return home) and radical economic policies (deregulation of labour market and privatisation)' (Blackmore 2004: 10). This has seen the subsequent dismantling of the gender equity structures, a concern with the effect of gender equity reform in education on boys, and the individualisation of disadvantage. In state governments which still had a Labour government, there has been an effort to counter these federal moves, but some trends have continued nonetheless, particularly the rise of "audit" culture and its impact on the culture of work within the bureaucracy.

The case from Australia, drawing extensively on Blackmore (2004) is used here to highlight the importance of viewing gender mainstreaming strategies in the context of the wider political, ideological and discursive shifts, as well as to demonstrate the multiple ways in which feminist advocacy and actions need to function in order to move forward equity reforms. This case demonstrates the complexity of change processes, and the impossibility of garnering impacts on all dimensions of social and political life through selected state-based strategies.

\section{Final thoughts ...}

As a construct gender mainstreaming constrains realistic assessment of change processes within bureaucratic institutions, and allows for the blurring of analysis of what are, fundamentally, political reform processes. Liberating gender mainstreaming from these shackles requires three actions - to discard the term altogether, and instead break up its component parts (policy reform, administrative reform, analytical and conceptual strengthening, political advocacy) and name each more accurately; to analyse gains and setbacks in terms of a disaggregated view of gender mainstreaming; and finally, to recognise the wider political contexts within which these component parts are operating.

Two specific issues are relevant here. First, as Standing argues (this IDS Bulletin) expectations of effecting social change through bureaucratic action alone are overwrought. Those who expect bureaucracies to effect miraculous impacts on women's gender identities and their relationships with men are inevitably confronted with the disappointing realisation that this is not what bureaucracies can do. Learning how best to leverage bureaucracies for transformative change requires some strategic rethinking. As Standing suggests, this may entail identifying what it is that bureaucracies are placed to deliver, and strengthening them to do so, within their operational mandates. Equally, where these operational mandates may not include an explicit commitment to serving citizens, it may mean finding ways to shift and expand them along broader axes of social and economic inequality and marginalisation.

Second, and following on from this, women (and men) within gender machineries and those who serve as intermediaries in the transformation project are unfairly sullied as somehow having failed this project. By expecting them to effect transformations and then criticising them for failing to do so, there is the danger of overlooking and negating the small victories that their presence and activism, however limited, may achieve. In particular, the danger is in overlooking their own battles with bureaucratic resistance, or with other forms of resistance in their personal lives. Models for understanding transformation and social change processes need to be applied not just to women out there, but also the women who work within these institutions, particularly in the uncelebrated gender machineries 
that have sprung up everywhere. Apart from Goetz's (2001) study of women development workers, which focused on grassroots intermediaries, there has been little effort to focus attention on intermediaries of change, who often suffer from an enormous burden of expectations, and are expected to succeed in environments often resistant or immune to ideas of social change.

The reduction of expectations from gender mainstreaming is a good starting point for a strategic rethink of what drives change on gender equity. Gender mainstreaming as a discourse and strategy has opened up critical spaces for starting to resource women's development, and in some areas, there have been significant shifts. That these shifts do not go far enough may just be a reflection of the limitations of the spaces within which these strategies are being played out, and also a reflection of the enormous difficulty of advocating social change more generally, particularly within current

\section{Notes}

1. This includes, for example, the recent UNICEF State of the World's Children 2004 report which focused on girls' education with the argument that 'In practice, almost all of the reforms undertaken to make the educational experience safer, more relevant and more empowering for girls also help boys' (UNICEF 2003: 59) or, in other words, 'educating girls is good for boys'.

\section{References}

Blackmore, J., 2004, 'Gender equity and resourcing: reflections from Australia', paper presented at the Beyond Access Forum, Oxford, 28 April

Bunting, M., 2004, 'Let's talk about sex', The Guardian, 29 May: 21

Fine, B., 2003, 'Neither the Washington nor the Post-Washington Consensus: An Introduction', in B. Fine, C. Lapavitsas and J. Pincus (eds), Development Policy in the Twenty-first Century: Beyond the Post-Washington Consensus, London: Routledge

Goetz, A.M., 2001, Women Development Workers: Implementing Rural Credit Programmes in Bangladesh, New Delhi: Sage Publications

Kanji, N. and Salway, S., 2000, 'Promoting equality between women and men', SD SCOPE Paper 2, Social Development Systems for Coordinated Poverty Eradication, University of Bath

Staudt, K., 1997, 'Gender Politics in Bureaucracy: Theoretical Issues in Comparative Perspective', neo-liberal and neo-conservative policy environments. Thus while rights may proliferate, the conditions under which women are exercising those rights are not necessarily improving. Further, the central conundrum which has trapped feminist advocacy in general is something that gender mainstreaming alone cannot tackle, or be held responsible for. This, as pithily put in a recent article in the Guardian newspaper, is the dilemma about how to 'reward and support [predominantly female] carers without institutionalising gender roles' (Bunting 2004). There is a need, therefore, to not get caught up in debates about whether gender mainstreaming is good or bad, a success or a failure, but instead to focus more on breaking down these processes of change, understanding them and the context in which they are being played out, and finding more appropriate labels to reflect what they really represent in terms of transformation.

in K. Staudt (ed.), Women, International Development, and Politics: The Bureaucratic Mire, Philadelphia: Temple University Press (updated and expanded edition)

Subrahmanian, R., 2004a, 'The politics of resourcing education: a review of new aid modalities from a gender perspective', paper presented at the Beyond Access Forum, Oxford 28 April

Subrahmanian, R., 2004b, 'Gender equity in education: a perspective from development', paper presented at Conference on Gender Equity in Education, Gordon's Bay, Cape Town 18-20 May

UNICEF, 2003, The State of the World's Children 2004: Girls, Education and Development, New York: The United Nations Children's Fund (UNICEF)

Whitehead, A., 2003, 'Failing women, sustaining poverty: gender in poverty reduction strategy papers', Report for the UK Gender and Development Network, May 